\title{
Reproductive biology of the sausage tree (Kigelia africana) in Kruger National Park, South Africa
}

\begin{tabular}{|c|c|}
\hline \multicolumn{2}{|c|}{$\begin{array}{l}\text { Authors: } \\
\text { Jah Namah }^{1} \text { @ } \\
\text { Jeremy J. Midgley }{ }^{1} \text { ( } \\
\text { Laurence M. Kruger }^{1,2} \text { @ }\end{array}$} \\
\hline \multicolumn{2}{|c|}{$\begin{array}{l}\text { Affiliations: } \\
{ }^{1} \text { Department of Biological } \\
\text { Sciences, University of } \\
\text { Cape Town, Cape Town, } \\
\text { South Africa }\end{array}$} \\
\hline \multicolumn{2}{|c|}{$\begin{array}{l}{ }^{2} \text { Organisation for Tropical } \\
\text { Studies, Skukuza, South Africa }\end{array}$} \\
\hline \multicolumn{2}{|c|}{$\begin{array}{l}\text { Corresponding author: } \\
\text { Jeremy Midgley, } \\
\text { jeremy.midgley@uct.ac.za }\end{array}$} \\
\hline \multicolumn{2}{|c|}{$\begin{array}{l}\text { Dates: } \\
\text { Received: } 11 \text { Dec. } 2017 \\
\text { Accepted: } 12 \text { Nov. } 2018 \\
\text { Published: } 29 \text { Apr. } 2019\end{array}$} \\
\hline \multicolumn{2}{|c|}{$\begin{array}{l}\text { How to cite this article: } \\
\text { Namah, J., Midgley, J.J. } \\
\text { \& Kruger, L.M., 2019, } \\
\text { 'Reproductive biology of } \\
\text { the sausage tree (Kigelia } \\
\text { africana) in Kruger National } \\
\text { Park, South Africa', Koedoe } \\
\text { 61(1), a1512. https://doi.org/ } \\
\text { 10.4102/koedoe.v61i1.1512 }\end{array}$} \\
\hline \multicolumn{2}{|c|}{$\begin{array}{l}\text { Copyright: } \\
\text { (c) 2019. The Authors. } \\
\text { Licensee: AOSIS. This v } \\
\text { is licensed under the } \\
\text { Creative Commons } \\
\text { Attribution License. }\end{array}$} \\
\hline \multicolumn{2}{|l|}{ Read online: } \\
\hline 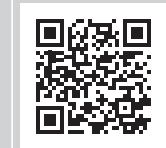 & $\begin{array}{l}\text { Scan this QR } \\
\text { code with your } \\
\text { smartphone or } \\
\text { mobile device } \\
\text { to read online. }\end{array}$ \\
\hline
\end{tabular}

Kigelia africana has large flowers that are vertebrate pollinated and very large fruits that are likely to be vertebrate dispersed. Our field surveys of size-class distributions of K. africana in the southern Kruger National Park (KNP) suggest a lack of recruitment. This is possibly the result of a failure of mutualistic relationships with vertebrate dispersers and/or pollinators. Breeding system experiments indicated that $K$. africana is an obligate out-crosser. Despite being primarily adapted for bat pollination, in KNP that K. africana is presently mainly pollinated by a diversity of largely facultatively nectarivorous bird species. Fruit-set is high, although trees isolated by $>50 \mathrm{~m}$ were found to suffer depressed seed output. Our preliminary investigation of dispersal suggests that fruits are largely ignored and are thus weakly attractive to potential dispersers. Seedlings placed out in the field in KNP suffered high levels (> 50\%) of mortality compared to $17.5 \%$ in control plots. This threefold difference is the result of herbivory over a 2-month period. In summary, the adult centric population structure is probably not because of pollen or seed limitation but may result from dispersal limitation or excessive herbivory.

Keywords: mutualisms; pollination; dispersal; Kigelia; sausage tree.

\section{Introduction}

The maintenance of mutualistic plant-animal interactions in and outside of conservation areas such as the Kruger National Park (KNP) has received relatively little attention compared to that devoted to disturbance by fire or herbivory. As an example, Midgley, Gallaher and Kruger (2012) and Midgley et al. (2015) recently argued that in KNP, elephants and squirrels are crucial to the dispersal and germination of marula (Sclerocarya birrea) and elephants are crucial for the dispersal and germination of torchwood (Balanites maughamii). Previously, Chapman, Chapman and Wrangham et al. (1992) argued for the importance of elephant dispersal of Balanites wilsoniana in Central Africa. Thus, the recruitment biology of certain trees in conservation areas would be threatened by the absence or decline of their elephant mutualists, for instance, through poaching for ivory.

Another species that appears to be particularly dependent on vertebrate pollination and dispersal mutualists is the iconic sausage tree, Kigelia africana (Bignoniaceae). This species has exceptionally large, wine-coloured flowers and large, sausage-shaped fruits that can grow $>0.5 \mathrm{~m}$ long and weigh several kilograms. Despite its apparent reliance on vertebrate mutualists, its reproductive biology (from flower to seedling) and relation to its demography has been poorly researched.

Kigelia africana flowers are considered to be chiropterophilous because they are large and open, robust and have a weak, unpleasant smell (Baker 1961). Flowers are visited by bats in some areas such as West Africa (Harris \& Baker 1958; Pettersson, Ervik \& Knudsen 2004), but there is no published evidence to date that they are visited by bats in Southern Africa (Johnson 2004), nor whether they require visits from pollinators to ensure seed-set. Although self-pollination is rare in the Bignoniaceae (e.g. Bertin, Barnes \& Guttman 1989; Gentry, 1974), it remains to be seen whether selfing occurs in K. africana. In addition to potential pollinator or lack of out-crossed pollen impacts on seed-set, seed dispersal limitation or excessive seedling herbivory could also impact the reproductive biology of K. africana. There have been no published studies on the dispersal of the sausage tree, despite popular speculations such as dispersal by a large diversity of vertebrates including rodents, mega-herbivores, primates and birds (Wikipedia 2017). Ansell (1965) reported the presence of K. africana seeds in the stomachs of 7 out of 10 hippopotamus in Zambia. 
This would be compatible with the tree's riverine distribution but not with the well-known grass-herb diet of hippos. Based on his dietary analysis, Field (1970) found Ansell's (1965) observation unusual, in part because 'the hippo is illequipped to feed on these fruits'. However, because the seeds are soft and embedded in the fruits, it is possible that more seeds would survive hippo ingestion than ingestion by other animals such as ungulates or baboons. In addition, because the fruits do not float (Laurence Kruger, personal observation [pers. obs.]), it is likely that they do need a disperser. The final step of recruitment is seedling establishment and again there have been few studies of herbivory rates on K. africana to determine whether it is relatively palatable. The aim of this study was to consider the reproductive biology of this species, from flowering to seedling recruitment, in the context of its overall demography within an area of the KNP.

\section{Materials and methods}

Because K. africana grows mostly in riverine systems, demographic surveys were conducted along three rivers (N'waswitsontso, Sabie and N'waswitshaka) close to Skukuza in the KNP (see Figure 1). Sampling was conducted between October 2012 and December 2012. The pollination and breeding system experiments were conducted inside or close to Skukuza Village.

\section{Demography}

To determine size-class distributions, we used 10 stratified $500 \mathrm{~m} \times 50 \mathrm{~m}$ transects on each of three riverbanks (see Figure 1 ), where we noted the diameter at breast height $(\mathrm{dbh}, 1.3 \mathrm{~m})$ of each tree. The diameter of the smaller trees $(<1.3 \mathrm{~m}$ in height) was taken at the base. To determine whether elephants negatively impact $K$. africana, we noted the presence of elephant damage to the stem (as the estimated percentage of stem circumference damaged). We also counted the number of fruits per individual tree. The latter measurement concerns the previous year's seed-set. Because individual trees may be tall and are not easily climbed, we estimated total numbers of fruits in groups of five when the number of fruits exceeded 20. In out-crossing species, isolated individuals may suffer depressed seed-set because of pollen limitation. We therefore also measured the distance in metres to the nearest mature conspecific individual using a range finder.

\section{Reproductive biology}

Pollination studies were conducted in Skukuza Village for safety reasons because many flowers needed to be observed, bagged or unbagged before dawn or after dusk. We expected fruit bats (especially Wahlberg's epauletted fruit bat, Epomophorus wahlbergi) to be the pollinator. These bats

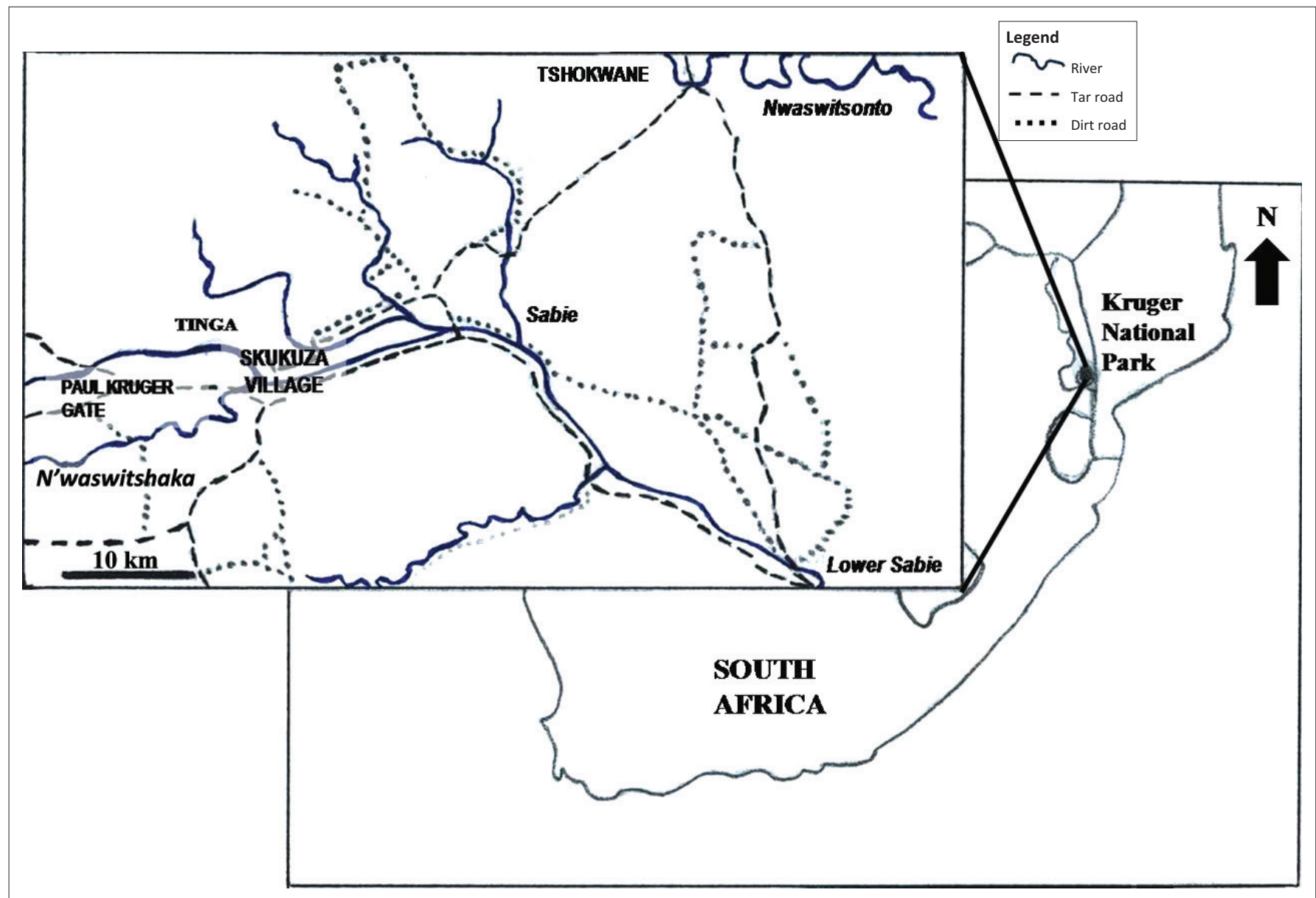

$\mathrm{km}$, kilometres.

FIGURE 1: Map of Kruger National Park, showing Skukuza Village and the three rivers (N'waswitsontso, Sabie and N'waswitshaka) where sampling of Kigelia africana took place. 
are widely observed roosting and feeding within Skukuza (Laurence Kruger, pers. obs.). Kigelia africana has a bilobed stigma, and the lobes are separate when the flower opens. As flowers only last one night (see below), we assumed that after the stigma lobes separate, the stigma is receptive. This was confirmed by seed-set results (see below). Freshly opened flowers from nine different trees (3-10 flowers per tree, depending on flower availability) in Skukuza were measured to quantify the nectar content and the timing of secretion. Buds were bagged before sampling, and freshly opened flowers were sampled at both dusk $(n=60)$ and dawn $(n=62)$ from all nine trees. We used a syringe to remove and measure the nectar. The sucrose equivalent concentration of the removed nectar was measured using an Eclipse refractometer.

To determine floral visitors, we also put up eight motionsensitive camera traps (Little Acorn TM1550): five in three sausage trees in Skukuza and three in two sausage trees in the more natural area of the nearby Tinga area (see Figure 1) from 20 September to 05 October 2012. The cameras were focused on opened inflorescences and the footage was checked every day, before refocusing the camera traps on newly opened flowers. We also observed individual trees in Skukuza Village for visitation, both in the evenings and at dawn, during the period September through October 2012.

To determine the impacts of various pollinators on fruit sets, bags from bagged flowers from 13 individual trees were opened and closed at specific times and with all four treatments (nocturnal, diurnal, open-pollination and total exclusion) being applied to all trees. These experiments were conducted within Skukuza Village from 24 September to 04 October 2012. To estimate the role of both diurnal (birds and mammals) and nocturnal pollinators (bats and galago species), bagged flowers were opened for a day or a night. To assess the contribution of birds to pollination, 150 bagged flowers were opened at dawn and left for $1 \mathrm{~h}$, after which they were all rebagged. To estimate the role of nocturnal animals, 150 bagged flowers were opened at dusk and were all rebagged $1 \mathrm{~h}$ before dawn. To determine the impacts of total pollinator exclusion, 123 flowers were bagged in bud and remained bagged for 5 weeks, and 150 control flowers were open all day and all night. After the 5 -week period, we visited the 13 trees and counted the number of developing fruits.

As a further test of the role of birds, we determined whether pollen was actually transferred to flowers after visitation by birds. We bagged buds on three trees; on the following day, these bags were opened between 03:30 and 05:30 (at dawn) and the flowers were observed. Those flowers that were observed to have been visited by any bird specie were later examined for the presence of conspecific pollen on the stigma.

To determine the breeding system, we bagged flower buds from 11 different trees from 01 October to 04 October 2012. Three treatments (crossed $=102$ flowers, selfed $=102$ and autogamy $=103$ ) were applied to all trees and flowers rebagged following treatment. After the flowers opened and the stigma lobes separated, we applied cross or self-pollen to a set of 5-10 flowers per tree, using a fine paintbrush to remove pollen and place it on stigmas. The brush was cleaned and washed between each use to avoid contamination. To assess autogamy, flowers were bagged without any further manipulation. We revisited these 11 trees on 21 November 2012 to determine the number of developing fruits.

\section{Herbivory}

To determine whether herbivores are attracted to K. africana and, if so, what the levels of seedling herbivory are, we produced a number of seedlings. To do this in October 2012, 500 seeds were extracted from freshly fallen sausage fruits and planted in paper cups (see Figure 2a). The 483 seedlings that germinated ( $97 \%$ germination rate) were grown and hardened in the nursery at Skukuza for 7 weeks (see Figure 2b). Thereafter, 420 seedlings were planted into savanna vegetation in groups of 10 per plot (plot $=25 \mathrm{~cm} \times$ $25 \mathrm{~cm}$ ) (see Figure 2c). Eight plots (total $n=80$ seedlings) were planted in savanna vegetation outside Skukuza Village where they were accessible to all herbivores, including mega-herbivores such as elephants. Eight plots were planted in savanna vegetation inside Skukuza Village, where megaherbivores are largely excluded. However, the seedlings were accessible to ungulate herbivores such as impala. As controls for these two treatments, eight matched plots were planted outside and inside the village and in this case seedlings were protected by wire enclosures, where no mammalian herbivores could access the seedlings apart from insects (see Figure 2d). Finally, 10 plots were planted inside a partial herbivore enclosure in the village, where only very small animals such as rodents and insects had access. The planted seedlings were left for 2 months and in January 2013 we counted the number of live seedlings. The difference between control plots and herbivore exclusion plots indicates the role of large herbivores in seedling mortality.

\section{Seed dispersal}

We collected fallen sausage fruits and placed them in groups of three to five fruits at the base of seven adult sausage trees in undisturbed areas to attract any potential disperser. Four cameras were each focused on a fruit pile near Skukuza and three cameras near Tinga (see Figure 1). The cameras were deployed continuously for 3 months from November 2012 to January 2013. The fruit piles were then checked for removal at the end of the research. Although no fruits were removed, the footage was also inspected to determine whether any mammals inspected the fruit.

\section{Results \\ Demography}

For the demographic survey, a total of 151 sausage trees were noted, with diameters ranging from $0.9 \mathrm{~cm}$ to $170 \mathrm{~cm}$. We found the distribution of large individuals similarly biased 

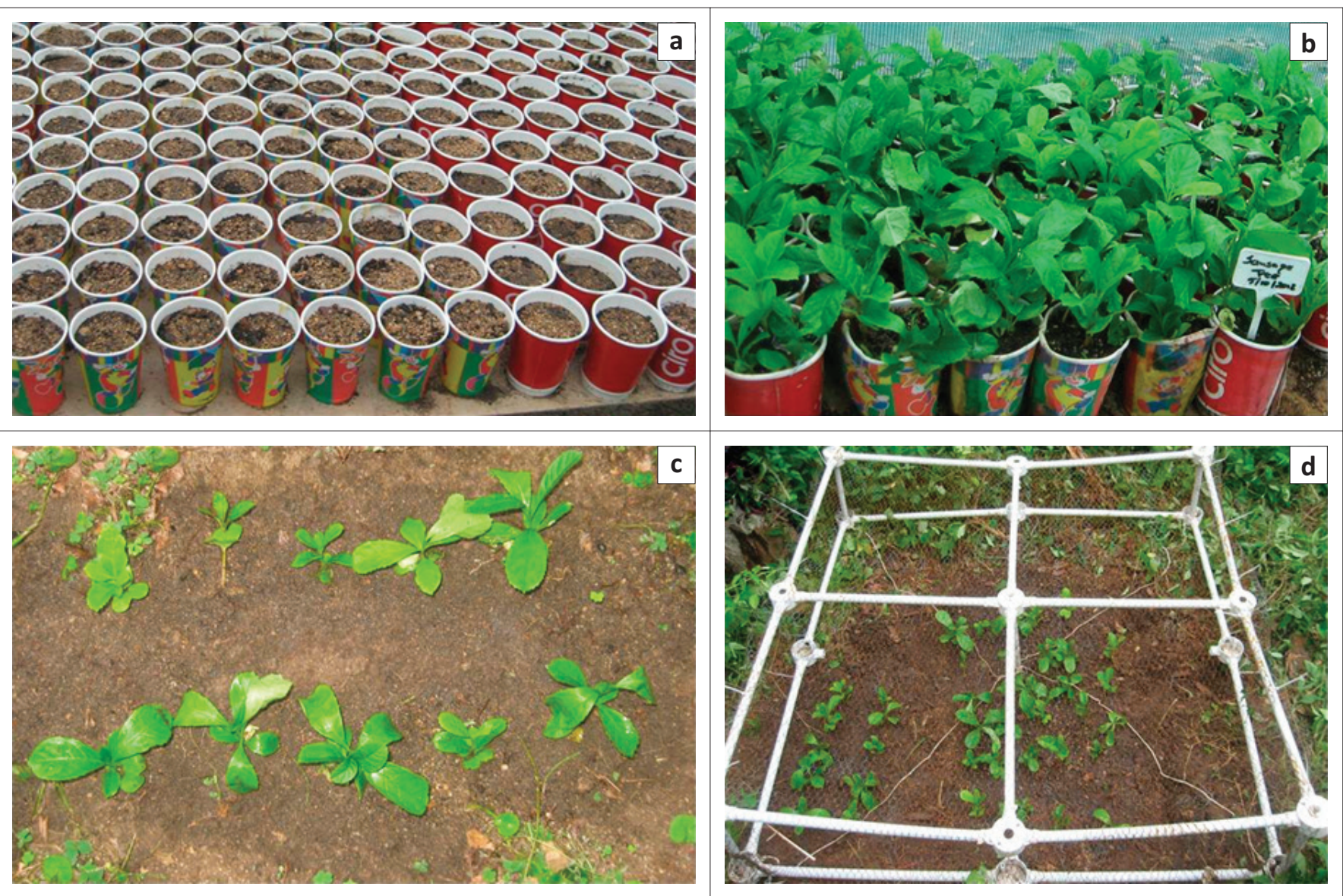

FIGURE 2: (a) Paper cups used for germination of Kigelia africana, (b) Kigelia africana seedlings before they were transferred to the ground for the herbivory experiment, (c) a plot of 10 planted seedlings, and (d) example of a wire-mesh enclosure used to exclude all herbivores.

on the three riverbanks. On N'waswitsontso, the ratio of recruitment $(<15 \mathrm{~cm}$ dbh): intermediate $(>15 \mathrm{~cm}$ and $<30 \mathrm{~cm}$ $\mathrm{dbh})$, large $(>30 \mathrm{~cm} \mathrm{dbh})$ was 8:14:100 $(n=122)$, whereas on Sabie it was 0:1:25 $(n=26)$, with no recruits and 0:0:3 on $\mathrm{N}^{\prime}$ waswitshaka $(n=3)$. The preponderance of large trees is demonstrated by the fact that of the $85 \%$ of trees that are $>30 \mathrm{~cm} \mathrm{dbh}, 87 \%$ of these are $>100 \mathrm{~cm}$ dbh. Only $22.5 \%$ of the individuals were found to have elephant bark-stripping marks on them, and because these were largely minor, the average percentage damage across all stems was very low $(<1 \%)$. No trees were found to have been uprooted by the elephants. Some canopy trees were found to have been toppled over because of flooding. Most of these toppled trees were found to resprout strongly.

\section{Reproductive biology}

Of the 770 flowers used in the pollination experiments, $96.4 \%$ lasted only one night before the corolla dropped off, while the remaining 28 flowers persisted for two nights. All the flowers opened only slightly before, at or after dusk. When the corolla opened, nectar was present and both lobes of the bilobed stigma were separate. The stigma lobes closed or at least partially closed within $5 \mathrm{~min}-15 \mathrm{~min}$ of being brushed with pollen. All the selfed flowers separated their stigma lobes again within an hour. Kigelia africana is an obligate out-crosser; no fruit formed when the flower was selfed or bagged (autonomous autogomy), whereas 81 of the 102 flowers that were crossed developed fruits.

The average amount of nectar in bagged flowers measured at dusk just after they had opened was high $(52.8 \mathrm{~mL}$, s.d. = $14.2, n=62)$, while the average in those measured at dawn after a night of having been opened but still bagged was low (14.8 mL, s.d. $=7.1, n=60$ ). We suspect this difference was because of a spillage of nectar (many bags had nectar on the bags and signs of damage to bags) by birds attempting to get at the nectar, rather than the reabsorption of nectar. The nectar had an average concentration of $15.9 \%$ (s.d. = 3.2) sucrose equivalent in the morning and $14.8 \%$ at dusk (s.d. $=3.2$ ).

\section{Pollinators}

We identified 12 different bird species visiting the flowers, and 10 of these species were observed feeding on the nectar (see Table 1 and Figure 3). We noted as many as 15 different bird visitations to a single flower during a 1-h observation period. Out of 90 marked flowers observed to have been visited by birds in a 1-h period, 70\% were later found to have pollen on their stigma, and only one flower had a missing stigma. This indicates that bird visitation causes pollen flow. Many flowers had major corolla lacerations such as large holes and ripped petals, presumably from bird claws. The camera footage captured several pollinators that were not directly observed. Table 2 summarises the potential pollinators observed (through 
TABLE 1: Direct and camera observations of various animal species that visited the flowers of Kigelia africana.

\begin{tabular}{|c|c|c|c|}
\hline Common name & Scientific name & $\begin{array}{l}\text { Observation } \\
\text { type }\end{array}$ & $\begin{array}{l}\text { Nectar } \\
\text { feeding }\end{array}$ \\
\hline Brown-headed parrot & Poicephalus cryptoxanthus & Direct & No \\
\hline Purple-crested turaco & Tauraco porphyreolopha & Direct & Yes \\
\hline Red-faced mousebird & Urocolius indicus & Direct & Yes \\
\hline White-eared barbet & Stactolaema leucotis & Direct & No \\
\hline Black-headed oriole & Oriolus larvatus & Direct & Yes \\
\hline $\begin{array}{l}\text { Dark-capped } \\
\text { (black-eyed) bulbul }\end{array}$ & Pycnonotus tricolor & Direct + camera & Yes \\
\hline Cape glossy starling & Lamprotornis nitens & Direct + camera & Yes \\
\hline $\begin{array}{l}\text { Scarlet-chested } \\
\text { sunbird }\end{array}$ & Chalcomitra senegalensis & Direct & Yes \\
\hline Southern masked weaver & Ploceus velatus & Direct & Yes \\
\hline Village weaver & Ploceus cucullatus & Direct & Yes \\
\hline $\begin{array}{l}\text { Yellow-fronted } \\
\text { canary }\end{array}$ & Crithagra mozambica & Direct & Yes \\
\hline Vervet monkey & Cercopithecus pygerythrus & Direct + camera & Yes \\
\hline $\begin{array}{l}\text { Green (red-billed) } \\
\text { wood hoopoe }\end{array}$ & Phoeniculus purpureus & Camera & Yes \\
\hline Thick-tailed bushbaby & Otolemur crassicaudatus & Camera & Yes \\
\hline $\begin{array}{l}\text { Large-spotted (Cape) } \\
\text { genet }\end{array}$ & Genetta tigrina & Camera & Yes \\
\hline
\end{tabular}

cameras and direct observation) in the act of visiting the flowers as well as whether or not they fed on nectar (see Figure $3 \mathrm{~b}-\mathrm{f})$. Bees were observed entering flowers to obtain nectar, but they were not perceived as potential pollinators as they did not touch the stigma. Neither during casual observations nor on camera were bats observed visiting flowers and we did not observe bat fur on stigmas.

Of the 150 control flowers open during both the night and subsequent morning to all pollinators, $54.3 \%$ set fruits, whereas for those open during the day for birds and those open at night, these values were $42.5 \%$ and $6.3 \%$, respectively. This nearly sevenfold difference indicates that birds are clearly the most important pollinating agents. Because we observed high bird attendance at flowers, the difference between the $80 \%$ of experimentally crossed flowers that set fruit, compared to only $54.3 \%$ of open flowers setting fruit, suggests that out-crossed pollen may be limiting. The minimum size for sexual maturity judged by the presence of fruits was $16.75 \mathrm{~cm} \mathrm{dbh}$. The maximum number of fruits per tree was 225 , with $35 \%$ of the 151 trees
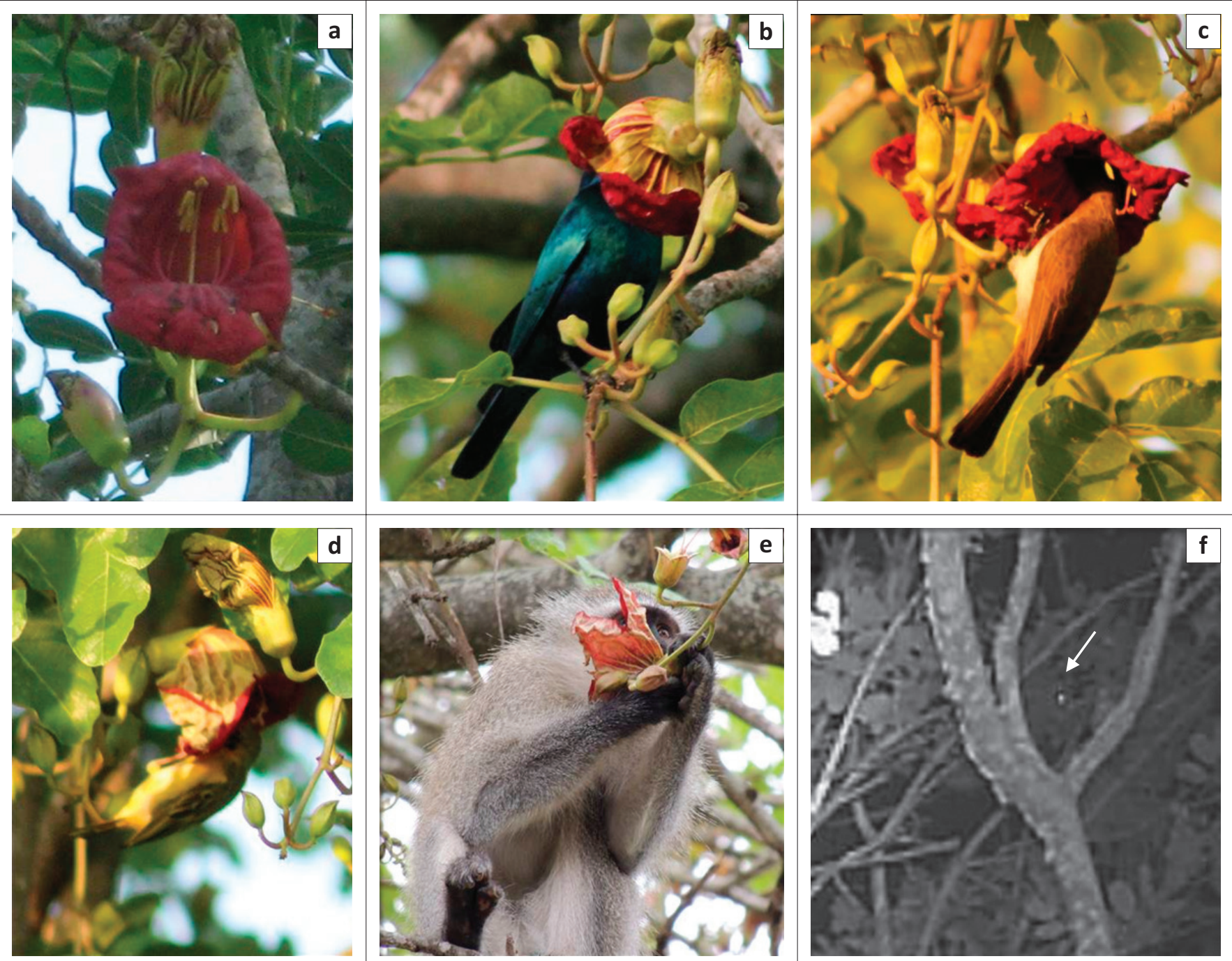

FIGURE 3: Kigelia africana and its various pollination vectors: (a) open flower and two buds on a stalk, (b) glossy starling (Lamprotornis nitens), (c) dark-capped bulbul (Pycnonotus tricolor) perching on the stalk and reaching for the nectar, (d) southern masked weaver (Ploceus velatus), clumsily perching on the flower petal to get to the nectar, (e) vervet monkey (Chlorocebus pygerythrus) lapping at the nectar, and (f) still of a video shot, illustrating a genet (Genetta tigrina) sniffing one of the flowers before placing its snout into the flower. 
producing 100 or more fruits. However, none of the 30 individual trees greater than $16.75 \mathrm{~cm}$ dbh but more than $45 \mathrm{~m}$ from another individual produced any fruits.

\section{Herbivory}

Over a 2-month period, mean mortality of $K$. africana seedlings was $17.5 \%$ in the control enclosures. This is more likely because of insect herbivores than because of drought as the experiment took place during the moist summer period. Mortality was $49.6 \%$ where all herbivores were present, suggesting this species is attractive to herbivores. The dominant herbivores were probably small herbivores $(64.6 \%$ mortality) rather than ungulates ( $31.7 \%$ mortality).

\section{Dispersal}

No fruits were taken and, despite analysing a total of $30.2 \mathrm{~h}$ of video footage from the camera traps, we found no animals seriously encountering the fruits, although we did see elephants occasionally sniffing at, but ignoring, them.

\section{Discussion}

Despite a generous definition of a recruit $(<15 \mathrm{~cm} \mathrm{dbh})$, recruits were few and were only found on one of the three rivers sampled. The widespread presence of fruits, except on isolated trees, and the many tens of easily germinating seeds per fruit yet a general lack of small plants suggests a recruitment bottleneck. Whether this bottleneck is a result of abiotic factors (such as episodic wet periods) or biotic factors (such as low hippopotamus populations) needs further research. Although the fruits are large, our analysis found that they are relatively unattractive to most large herbivore dispersers, at least during summer. Although our germination rates of untreated seeds were high, this applies to seeds removed from fruits. Given the hard skin of the fruits and the soft nature of the seeds, it is unlikely that germination would take place in intact, undispersed, dried-out fruits. Similarly, we suspect that the soft seeds would not survive mastication by ungulates or elephants. Thus, germination initiation and dispersal limitation may be a part of the recruitment bottleneck, and dispersal experiments targeted at hippos would be valuable. Seedling herbivory is intense and could also be an important key to the 'missing' juvenile-size classes. However, at least at this stage, it cannot be argued that herbivory is excessive (i.e. more than could be reasonably expected). If it were shown that higher recruitment levels resulting from better seed dispersal were associated with disproportionately more seedlings escaping herbivory, then dispersal failure might explain the low recruitment.

There are several indications that this species is an obligate out-crosser. Selfing resulted in zero fruit development; the stigma lobes reseparated after selfed pollen was placed on them, and isolated trees set few fruits. In addition, the style is longer than the anthers and this prevents pollen passively arriving on the stigma. Despite K. africana being an outcrosser and ostensibly bat-pollinated, in KNP it is heavily visited and successfully pollinated by generalist diurnal birds rather than nocturnal mammals. It is well known that not all bird-pollinated plants are pollinated by specialist nectarivores, such as sunbirds and hummingbirds (e.g. Johnson \& Nicholson 2008). The situation with K. africana is different in that it has many bat-pollinated (not birdpollinated) traits such as large, open, night-time opening flowers. Nevertheless, large amounts of sugary nectar that is easily accessible attract a diversity of diurnal vertebrate visitors to the flowers. Thus, surprisingly, a breakdown in bat pollination has probably not been an important factor in determining the skewed demography.

Whether aspects of global change will negatively impact plant-animal interactions, and thus plant extinction, in nature reserves it is a complex question. For instance, this depends on how persistent the plants are and whether other mutualists can replace lost mutualisms, such as generalist birds having replaced bats as pollinators of $K$. africana in KNP. Some plants have survived long-term failed interactions (i.e. anachronistic mutualisms), such as where large animals were extinguished by expanding human populations (Janzen \& Martin 1982). Survival of these anachronistic plants can result from the plants being highly persistent (sensu Bond \& Midgley 2001) and in other cases if dispersal is rescued by domestic animals (Janzen \& Martin 1982). We noted that toppled K. africana can resprout and therefore the species has a degree of persistence. Further work is needed on the dispersal of K. africana in other areas to determine its reliance on ingestion and dispersal for recruitment and local impacts of herbivores.

\section{Acknowledgements}

The authors thank SANParks for permission to work in KNP and the National Research Foundation for funding provided to J. Midgley.

\section{Competing interests}

The authors declare that they have no financial or personal relationships that may have inappropriately influenced them in writing this article.

\section{Authors' contributions}

J.J.M. designed this master's project and supervised the analyses and write-up. J.N. did all the fieldwork, analyses and writing. L.M.K. supervised and participated in the fieldwork.

\section{Funding information}

Funding for this study was provided by the National Research Foundation.

\section{References}

Ansell, W.F.H., 1965, 'Feeding habits of Hippopotamus amphibious Linn', Puka 3, 171. Baker, H.G., 1961, 'The adaptation of flowering plants to nocturnal and crepuscular pollinators', The Quarterly Review of Biology 36, 64-73. https://doi.org/10.1086/ 403276 
Bertin, I.R., Barnes, C. \& Guttman, I.S., 1989, 'Self-sterility and cryptic self-fertility in Campsis radicans (Bignoniaceae)', Botanical Gazette 150, 397-403. https://doi. org/10.1086/337785

Bond, J.W. \& Midgley, J.J., 2001, 'Ecology of sprouting in woody plants: The persistence niche', Trends in Ecology and Evolution 16(1), 45-51. https://doi.org/10.1016/ S0169-5347(00)02033-4

Chapman, L.J., Chapman, C.A. \& Wrangham, R.W, 1992, 'Balanites wilsoniana: Elephant dependent dispersal?', Journal of Tropical Ecology 8(3), 275-283. https://doi.org/10.1017/S0266467400006519

Field, C.R., 1970, 'A study of the feeding habits of the hippopotamus (Hippopotamus amphibius Linn.) in the Queen Elizabeth National Park, Uganda, with some management implications', Zoologica Africana 5, 71-86. https://doi.org/10.1080/ 00445096.1970 .11447382

Gentry, H.A., 1974, 'Coevolutionary patterns in Central American Bignoniaceae', Annals of the Missouri Botanical Garden 61, 728-759. https://doi.org/10.2307/ 2395026

Harris, B.J. \& Baker, H.G., 1958, 'Pollination in Kigelia africana Benth', Journal of the West African Science Association 4, 25-30.
Janzen, D.H. \& Martin, P.S., 1982, 'Neotropical anachronisms: The fruits the gomphotheres ate', Science 215, 19-27. https://doi.org/10.1126/science.215.4528.19

Johnson, S.D., 2004, 'An overview of plant-pollinator relationships in southern Africa', International Journal of Tropical Insect Science 24, 45-54. https://doi. org/10.1079/IJT20043

Johnson, S.D. \& Nicholson, S.W., 2008, 'Evolutionary associations between nectar properties and specificity in bird pollination systems', Biology Letters 4, 49-52. https://doi.org/10.1098/rsbl.2007.0496

Midgley, J.J., Gallaher, K. \& Kruger, L.M., 2012. 'The role of the elephant (Loxodonta africana) and the tree squirrel (Paraxerus cepapi) in marula (Sclerocarya birrea) seed predation, dispersal and germination', Journal of Tropical Ecology 28 , 227-231. https://doi.org/10.1017/S0266467411000654

Midgley, J.J., Kruger, L.M., Viljoen, S., Bijl, A. \& Steenhuisen, S.-L., 2015, 'Fruit and seed traits of the elephant-dispersed African savanna plant Balanites maughamii', Journal of Tropical Ecology 31, 557-561. https://doi.org/10.1017/S0266467415000437

Pettersson, S., Ervik, F. \& Knudsen, T.J., 2004, 'Floral scent of bat-pollinated species: West Africa vs. the new world', Biological Journal of the Linnean Society 82 161-168. https://doi.org/10.1111/j.1095-8312.2004.00317.x 